Article

\title{
Direct Ethanol Production from Xylan and Acorn Using the Starch-Fermenting Basidiomycete Fungus Phlebia acerina
}

\author{
Kenji Okamoto*(D), Takato Goda, Takeru Yamada and Masafumi Nagoshi \\ Department of Chemistry and Biotechnology, Graduate School of Engineering, Tottori University, \\ Tottori 680-8552, Japan; takato.gouda.tottoridaigaku@gmail.com (T.G.); takerukar93@gmail.com (T.Y.); \\ q.s16555i@gmail.com (M.N.) \\ * Correspondence: okamoto@tottori-u.ac.jp
}

Citation: Okamoto, K.; Goda, T.; Yamada, T.; Nagoshi, M. Direct

Ethanol Production from Xylan and Acorn Using the Starch-Fermenting Basidiomycete Fungus Phlebia acerina. Fermentation 2021, 7, 116. https:// doi.org/10.3390/fermentation7030116

Academic Editors: Ana Susmozas and Aleta Duque

Received: 11 June 2021

Accepted: 12 July 2021

Published: 15 July 2021

Publisher's Note: MDPI stays neutral with regard to jurisdictional claims in published maps and institutional affiliations.

Copyright: (c) 2021 by the authors. Licensee MDPI, Basel, Switzerland. This article is an open access article distributed under the terms and conditions of the Creative Commons Attribution (CC BY) license (https:/ / creativecommons.org/licenses/by/ $4.0 /)$.
Abstract: During our search for ethanol-producing basidiomycete fungi for a wide range of substrates, we isolated Phlebia acerina, which is a white rot basidiomycete fungus. It favorably converted starch into ethanol with approximately $70 \%$ yield. Although the yield decreased as the starch concentration increased, growth and fermentation were observed even at $200 \mathrm{~g} / \mathrm{L}$ of starch. P. acerina produced ethanol from glucose, galactose, mannose, xylose, cellobiose, and maltose with $93 \%, 91 \%, 86 \%$, $72 \%, 92 \%$, and $68 \%$ yields, respectively. Additionally, P. acerina, which secreted xylanase and xylosidase, was capable of assimilating xylan and directly converting it to ethanol with a yield of $63 \%$. Furthermore, P. acerina produced ethanol directly from acorns, which are plant fruits containing starch and tannins, with a yield of $70 \%$. Tannin delayed mycelia growth, thus prolonging ethanol production; however, this did not particularly affect the yield. These results were similar to those of fermentation in a medium with the same amounts of starch and tannin as the target crop acorn, thus suggesting that $P$. acerina could successfully produce environmentally friendly ethanol from starchcontaining lignocellulosic biomass, unlike previously reported ethanol-producing basidiomycete fungi.

Keywords: basidiomycete; Phlebia acerina; ethanol; fermentation; xylan; acorn

\section{Introduction}

The Earth's atmosphere contains traces of greenhouse gases (GHGs), such as carbon dioxide, methane, nitrous oxide, and chlorofluorocarbons, all of which absorb and re-emit infrared radiation. Infrared radiation emitted from the surface of the earth is trapped in the atmosphere as heat and is returned to the surface of the earth, thereby warming the atmosphere near the surface of the earth and maintaining an environment conducive for living for various organisms. However, increase in the atmospheric GHG concentration increases the surface temperature of the earth excessively. This is a major cause of global warming. Since the Industrial Revolution of the 18th century, use of fossil fuels, such as coal, oil, and natural gas, has increased exponentially to support global economic growth, thereby rapidly increasing GHG emissions [1]. Fossil fuels are common energy sources for daily consumption, but recently, efforts have been made worldwide to reduce GHGs to reduce the rate of global warming. The International Council on Clean Transportation has suggested that fossil fuels should be replaced with low-carbon alternative energy sources, such as solar, wind, and biofuels.

Carbon dioxide released during bioethanol burning is absorbed by plants that serve as raw materials for bioethanol, and is an energy source for plants during photosynthesis. Bioethanol is a carbon-neutral renewable fuel that does not emit toxic substances such as those emitted during fossil fuel burning, and can continuously generate energy. Bioethanol production from crops, such as corn and sugarcane, has been practically applied; however, concerns regarding potential food shortages due to the exponentially growing population 
have shifted the focus to ethanol production from inedible plant materials such as grass, trees, and used paper.

To ensure environmental conservation, food production and economic growth are balanced through bioethanol production using recombinant microorganisms that are designed to ferment different sugars produced from hydrolysis of inedible starchy or lignocellulosic materials [2-5].

Hemicelluloses are a heterogeneous class of polymers representing $15-35 \%$ of lignocellulosic biomass, and contain pentoses ( $\beta$-D-xylose and $\alpha$-L-arabinose), hexoses ( $\beta$ $D$-mannose, $\beta$-D-glucose, and $\alpha$-D-galactose), and /or uronic acids ( $\alpha$-D-glucuronic, $\alpha$ D-4-O-methylgalacturonic, and $\alpha$-D-galacturonic acids) [6-8]. Xylan, a heteropolymer consisting of $\beta-1,4$ bonds of xylose that partially contains uronic acid and arabinose, is the main component of hemicelluloses. The use of xylan, which consists of C5 sugars, is also important when considering ethanol production from lignocellulosic resources. Two main enzymes are involved in xylan degradation: endo-1,4- $\beta$-xylanase (EC 3.2.1.8), which randomly cleaves the main chain of xylan to produce xylooligosaccharides, and $\beta$-xylosidase (EC 3.2.1.37), which directly hydrolyzes non-reducing ends of xylan and xylooligosaccharides to xylose [9]. Acquiring and fermenting xylose by hydrolysis and fermenting xylan with a recombinant microorganism having exogenous endoxylanase and $\beta$-xylosidase genes are major methods of ethanol production from xylan [10-12].

Acorns, fruits belonging to the Fagaceae family, grow naturally in mountainous regions, and comprise starch, phenolic compounds, fatty acids, protein (gluten free), fiber, and ash. They are edible and exhibit a bitter taste because of tannins, which are plant poly phenolic compounds. Recently, acorns have been gaining attention as a cost-effective and sustainable food resource [13-15]. Lithocarpus edulis is a fast-growing and durable tree that does not require heavy maintenance and is resistant to sea breezes, diseases, and desiccation. It is a common roadside tree planted in urban areas. However, the acorns falling from L. edulis are collected as waste and incinerated. Tannins, which are structurally similar to catechins, exhibit strong antibacterial properties [16]. Several studies on butanol, ethanol, and citric acid production from acorn starch have been reported, but these studies focus on methods to remove tannins, which inhibit fermentation through pretreatment [17-21].

Basidiomycete fungi are forest decomposers exhibiting lignocellulosic decomposing ability, while some, such as yeast, exhibit fermentability and can produce ethanol from lignocellulosic biomass [22-26]. Furthermore, several studies have focused on the fermentability of wild basidiomycete fungi and revealed that ethanol can be produced from unused resources, such as rice straw, wheat bran, kitchen waste, whey, and expired milk [27-33]. Since these bioethanol production methods do not use recombinant microorganisms, they are environmentally friendly and can be used for regional on-site production.

Our investigation on the ethanol fermentability of wild basidiomycete fungi has resulted in the isolation of a new strain belonging to the genus Phlebia that exhibits interesting fermentation properties compared with previously reported ethanol-producing basidiomycete fungi. Therefore, in this study, we aimed to conduct a detailed examination on the fermentability of the recently isolated mushroom strain, Phlebia acerina, on various raw materials, such as xylan and acorns.

\section{Materials and Methods}

\subsection{Microorganisms and Culture Conditions}

Phlebia acerina SF23754, isolated in the Tottori Prefecture, Japan, was grown on 1.5\% agar plates consisting of malt extract-yeast extract-glucose (MYG) medium $(10 \mathrm{~g} / \mathrm{L}$ malt extract, $4 \mathrm{~g} / \mathrm{L}$ yeast extract, and $4 \mathrm{~g} / \mathrm{L}$ glucose). The strain was identified using standard morphological and biochemical analyses, at TechnoSuruga Laboratory Co., Ltd. (Shizuoka, Japan), and by sequencing the 28S rDNA D1/D2 domain and the internal transcribed spacer (ITS) region within 5.8S rDNA. According to the morphological, biochemical, and phylogenetic analyses, SF23754 was identified as P. acerina. Other basidiomycete fungi 
used in this study were preserved strains acquired from the Fungus/Mushroom Resource and Research Centre of Tottori University (Tottori, Japan), except for Trametes versicolor KT9427 [31] and Peniophora sp. YM5314 [32].

The strains were grown on MYG agar plates for 5-14 d; subsequently, three $0.5 \mathrm{~cm}^{2}$ pieces of the mycelia were inoculated into a $500 \mathrm{~mL}$ Erlenmeyer flask containing $100 \mathrm{~mL}$ of medium $(10 \mathrm{~g} / \mathrm{L}$ yeast extract and $20 \mathrm{~g} / \mathrm{L}$ of the test carbon source, without $\mathrm{pH}$ adjustment). The cultures were incubated at $30^{\circ} \mathrm{C}$ on a rotary shaker (BR-23FP-MR, Taitec Corp., Saitama, Japan) at $120 \mathrm{rpm}$. Each experiment was performed in triplicate.

Soluble starch (Nacalai Tesque, Inc., Kyoto, Japan) was used only when investigating changes in concentration, whereas corn starch (Nacalai Tesque, Inc., Kyoto, Japan) was used in the other experiments. To investigate the effect of starch concentration on ethanol production, a medium was prepared by adding $50-200 \mathrm{~g} / \mathrm{L}$ soluble starch to $10 \mathrm{~g} / \mathrm{L}$ yeast extract, autoclaved, inoculated with mycelia, and cultured with shaking at $30^{\circ} \mathrm{C}$. Xylan derived from corn core (Tokyo Chemical Industry Co., Ltd., Tokyo, Japan), which is cheaper and more readily available than that derived from trees, was used as the fermentation substrate. To investigate the effect of ethanol production on xylan concentration, a medium was prepared by adding 20-100 g/L starch to $10 \mathrm{~g} / \mathrm{L}$ yeast extract, autoclaved, inoculated with mycelia, and cultured with shaking at $30^{\circ} \mathrm{C}$. The acorns used in this study were collected from L. edulis, which possess acorns with low tannin levels. Acorn shells were removed, and acorn kernels were crushed and finely ground in a mortar. The acquired acorn powder, which contained approximately $60 \%$ starch, approximately $1 \%$ tannins, and other trace proteins, fats, etc., was prepared for experimentation. The culture medium used for investigating ethanol production from acorn comprised $10 \mathrm{~g}$ acorn powder and $90 \mathrm{~mL}$ water in a $500 \mathrm{~mL}$ Erlenmeyer flask, without $\mathrm{pH}$ adjustment. The prepared media were sterilized in an autoclave at $121^{\circ} \mathrm{C}$ for $15 \mathrm{~min}$ prior to use.

\subsection{Enzyme Activity Assays}

Endo-1,4- $\beta$-xylanase and $\beta$-xylosidase activities were measured using Ramazol Brilliant Blue R-D-Xylan and 4-Nitrophenyl $\beta$-D-xylopyranoside (Sigma-Aldrich, St. Louis, MO, USA), respectively [34]. Furthermore, the activities of $\alpha$-amylase, $\alpha$-glucosidase, and glucoamylase in culture filtrates during fermentation of starch and acorn were assayed using commercial kits from Kikkoman Corp. (Chiba, Japan).

\subsection{Analytical Methods}

Ethanol and residual sugar concentrations in culture filtrates were determined using the Prominence high-performance liquid chromatography (HPLC) system (Shimadzu Corp., Kyoto, Japan) equipped with an RID-10A refractive index detector (Shimadzu) and a Shodex KS-801 column $(8.0 \mathrm{~mm} \times 300 \mathrm{~mm}$; Showa Denko Co., Ltd., Tokyo, Japan) operating at $80{ }^{\circ} \mathrm{C}$ with a mobile phase of distilled water at a flow rate of $0.6 \mathrm{~mL} / \mathrm{min}$. The theoretical ethanol yield was $0.51 \mathrm{~g}$ ethanol $/ \mathrm{g}$ monosaccharide and $0.54 \mathrm{~g}$ ethanol $/ \mathrm{g}$ disaccharide, whereas it was $0.57 \mathrm{~g}$ ethanol $/ \mathrm{g}$ polysaccharide when xylan or starch was used as the only carbon source. Total phenolic content was measured by the Folin-Ciocalteu method [35].

\section{Results and Discussion}

\subsection{Selection of Starch-Fermenting Strain}

Using T. versicolor KT9427 and Peniophora sp. YM5314, which showed excellent starch fermentability in our previous studies [31,32], as indicators, the fermentability of 15 strains that showed relatively good growth in a medium containing $20 \mathrm{~g} / \mathrm{L}$ of starch was compared. The ethanol-producing yield of P. acerina SF23754 strain was the highest among the studied strains after $144 \mathrm{~h}$ of cultivation (Figure 1). Therefore, it represented an excellent starchfermenting basidiomycete fungus and thus, was used for further investigation. 


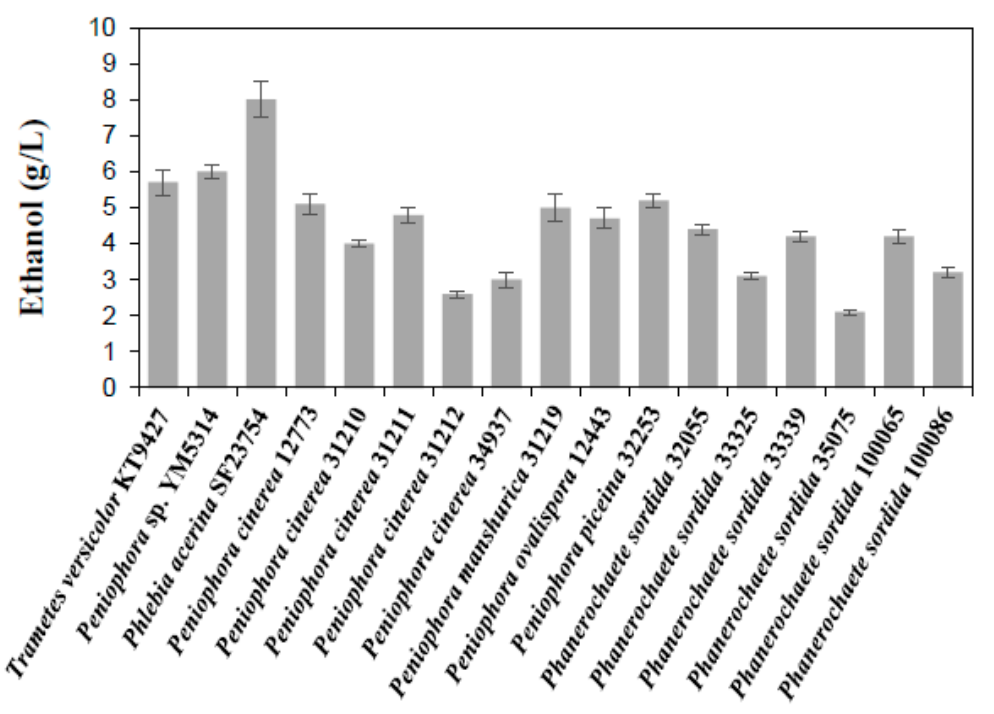

Figure 1. Screening of basidiomycete fungus capable of directly fermenting starch. Gray bars represent ethanol. Standard deviations were derived from ten independent experiments and are indicated by error bars.

\subsection{Effect of Starch Concentration on Mycelial Growth and Ethanol Production}

The effect of increasing starch concentrations on mycelial growth and ethanol production was investigated, during which saccharification treatment, such as enzyme addition, was not performed. Consequently, growth was observed up to $200 \mathrm{~g} / \mathrm{L}$ of starch, and ethanol concentrations acquired in 50,100, 150, and $200 \mathrm{~g} / \mathrm{L}$ starch were 21, 39, 46, and $47 \mathrm{~g} / \mathrm{L}$, respectively, whereas the ethanol yields per added gram of starch were $74 \%, 68 \%$, $54 \%$, and $41 \%$, respectively (Figure $2 \mathrm{a}-\mathrm{d}$ ). However, the ethanol conversion rate per sugar consumed was almost the same, and the ethanol yield per sugar tested decreased as the starch concentration increased, which in turn was influenced by the tolerance to ethanol concentration. High glucose amounts were detected during fermentation according to the tested starch concentrations. Furthermore, when the starch concentration was $100 \mathrm{~g} / \mathrm{L}$ or more, the ethanol yield decreased as the concentration increased. Nonetheless, mycelial growth and ethanol production were observed up to $200 \mathrm{~g} / \mathrm{L}$, which was the concentration range in which the test was conducted. Therefore, the naturally occurring basidiomycete fungus, P. acerina SF23754, exhibited relatively strong sugar resistance and excellent ethanol production ability from starch, which was comparable with the yield acquired by recombinant Saccharomyces cerevisiae integrated with $\alpha$-amylase and glucoamylase genes [36].

\subsection{Fermentability of Phlebia acerina SF23754 in Different Sugars}

The fermentability performance of $P$. acerina SF23754 was investigated in a culture medium supplemented with monosaccharide glucose, galactose, mannose, and xylose as the only carbon sources. Subsequently, each sugar except xylose was almost consumed within $72 \mathrm{~h}$ (Figure 3a-d), after which the maximum ethanol concentrations of 9.5, 9.3, 8.8, and $7.3 \mathrm{~g} / \mathrm{L}$, which corresponded to ethanol yields of $0.48,0.47,0.44$, and $0.40 \mathrm{~g}$ ethanol per $\mathrm{g}$ sugar consumed for glucose, galactose, mannose, and xylose, respectively, were observed. However, the fungus did not grow well on arabinose, which is a C5 sugar the same as xylose, and thus, ethanol was not produced (data not shown). Thus, P. acerina SF23754 effectively fermented monosaccharides and produced ethanol not only from hexose sugar but also from pentose sugar. When the strain SF23754 was cultured on a medium containing disaccharides cellobiose and maltose, the carbon sources were gradually decomposed, with maximum ethanol concentrations of 9.9 and $7.3 \mathrm{~g} / \mathrm{L}$, respectively, acquired after complete consumption of the sugars at $144 \mathrm{~h}$ and $192 \mathrm{~h}$, respectively (Figure $4 \mathrm{a}, \mathrm{b}$ ). The observed ethanol yields of $0.50 \mathrm{~g}$ and $0.37 \mathrm{~g}$ ethanol per $\mathrm{g}$ sugar consumed for cellobiose and maltose, 
respectively, demonstrated that $P$. acerina SF23754 effectively converted both the sugars to ethanol.

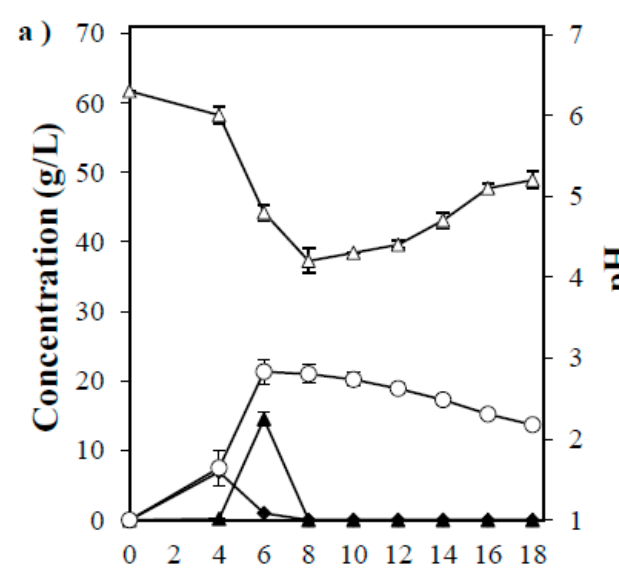

Time (h)

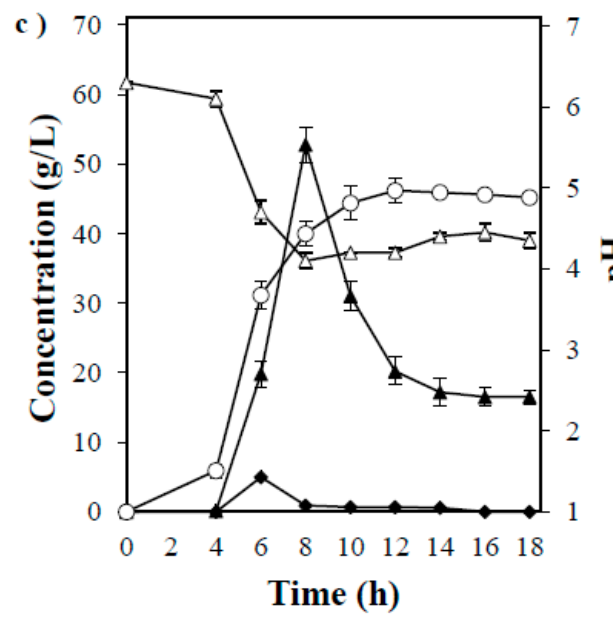

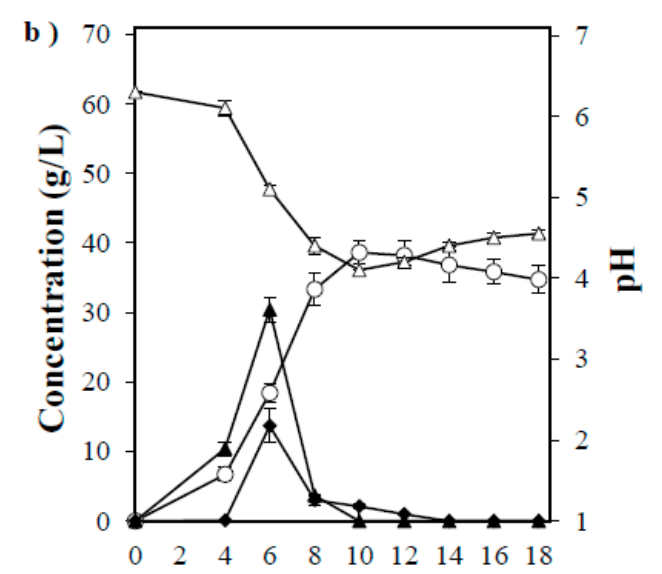

Time (h)

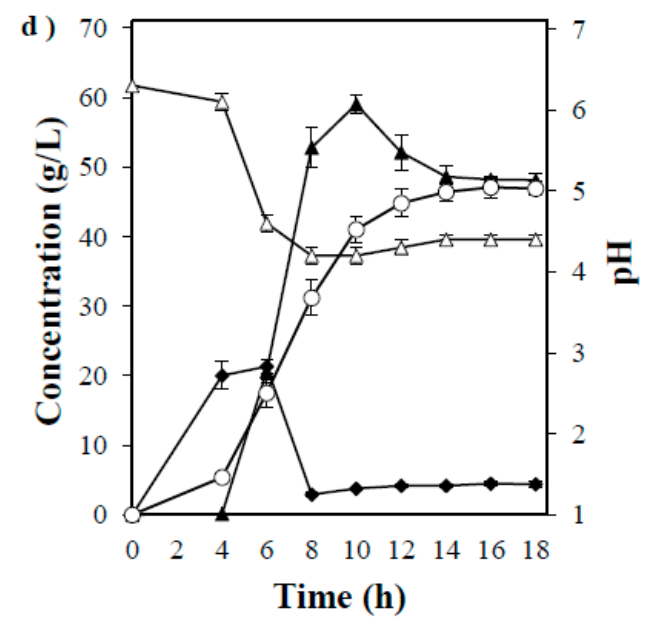

Figure 2. Timeline of ethanol production by P. acerina SF23754 using (a) $50 \mathrm{~g} / \mathrm{L}$, (b) $100 \mathrm{~g} / \mathrm{L}$, (c) $150 \mathrm{~g} / \mathrm{L}$, and (d) $200 \mathrm{~g} / \mathrm{L}$ of starch, and $10 \mathrm{~g} / \mathrm{L}$ of yeast extract. Closed diamonds and triangles represent maltose and glucose, respectively, whereas open circles and triangles represent ethanol and $\mathrm{pH}$, respectively. Standard deviations were derived from three independent experiments and are indicated by error bars.

In contrast, P. acerina SF23754 fermented starch in the abovementioned fermentation tests but its fermentability for maltose was unexpectedly low. To further confirm this observation, fermentability for maltose was investigated at different concentrations; however, compared with cellobiose, the mycelia growth and ethanol yield was low $(0.26$ and $0.43 \mathrm{~g} / \mathrm{g}$ at 10 and $30 \mathrm{~g} / \mathrm{L}$, respectively). The sensitivity to maltose may be high only during the early stage of mycelial growth, as fermentability is not affected by maltose once the mycelia have reached a certain growth stage. This result slightly differs from observations in previously isolated fermentable basidiomycete fungi [31,32]. 

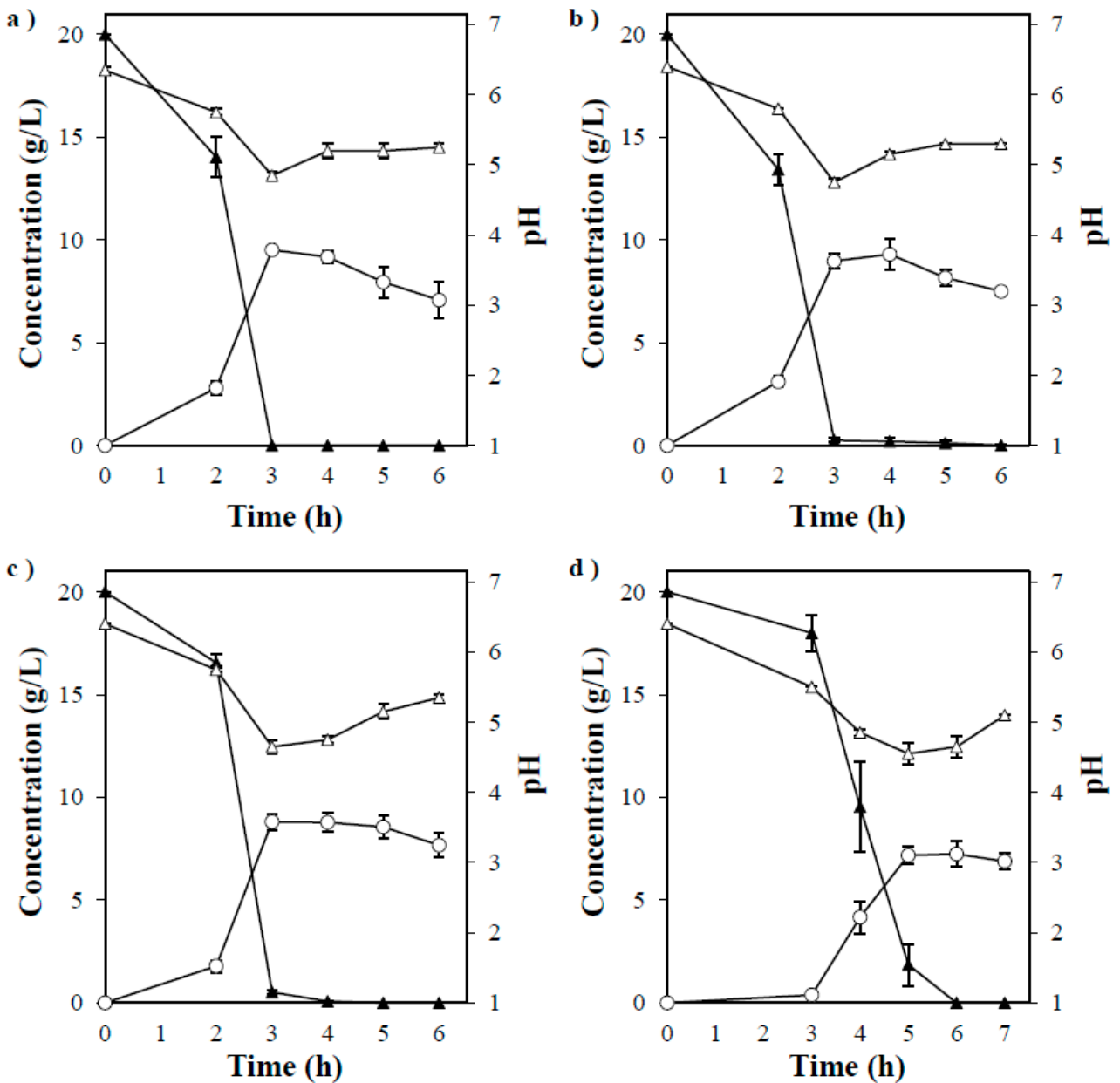

Figure 3. Timeline of ethanol production by P. acerina SF23754 using $20 \mathrm{~g} / \mathrm{L}$ of (a) glucose, (b) galactose, (c) mannose, and (d) xylose as the only carbon sources, and $10 \mathrm{~g} / \mathrm{L}$ of yeast extract. Closed triangles, open circles, and open triangles represent monosaccharides, ethanol, and $\mathrm{pH}$, respectively. Standard deviations were derived from three independent experiments and are indicated by error bars.
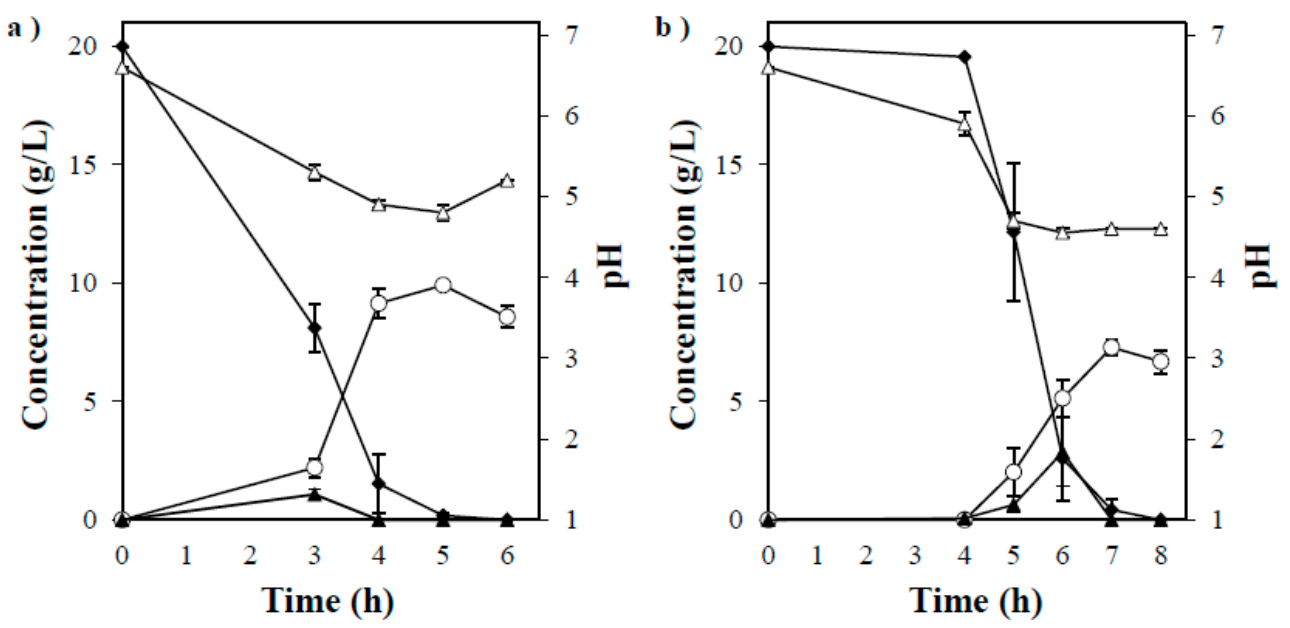

Figure 4. Timeline of ethanol production by P. acerina SF23754 using $20 \mathrm{~g} / \mathrm{L}$ of (a) cellobiose and (b) maltose as the only carbon sources, and $10 \mathrm{~g} / \mathrm{L}$ of yeast extract. Closed diamonds and triangles represent disaccharides and glucose, respectively, whereas open circles and triangles represent ethanol and $\mathrm{pH}$, respectively. Standard deviations were derived from three independent experiments and are indicated by error bars. 


\subsection{Direct Ethanol Production from Xylan}

As described above, P. acerina SF23754 efficiently converted xylose to ethanol. Therefore, we investigated the mycelia growth and xylan fermentability. When cultured in a medium containing 20,50, and $100 \mathrm{~g} / \mathrm{L}$ of xylan, sufficient growth was observed similar to the observations in the medium containing xylose (Figure 5a-c). Significant amounts of xylobiose, xylotriose, and xylooligosaccharides were released during fermentation, and they increased depending on the xylan concentration. Subsequently, the released compounds were consumed as the culture progressed. Conversely, xylose was almost undetected irrespective of the concentration of xylan, which was probably consumed rapidly by the cells. The ethanol concentrations in 20,50, and $100 \mathrm{~g} / \mathrm{L}$ of the xylan medium were $7.2,17$, and $21 \mathrm{~g} / \mathrm{L}$, respectively, and the yields per added amount of xylan were $63 \%, 60 \%$, and $37 \%$, respectively. The values represent the yields for the xylan amounts added, and not the xylan amount consumed. This conversion rate from xylan to ethanol was higher than various genetically modified microorganisms, such as recombinant Klebsiella oxytoca and recombinant xylan-fermenting S. cerevisiae strains [10-12]. Recombinant microorganisms reportedly showed a maximum ethanol yield of $54 \%$ per sugar consumption, but only a part of the added xylan was converted to ethanol, while most remained unutilized. This could possibly be because catabolite repression of the produced xylose suppresses the decomposition of xylan, xylooligosaccharide, and xylobiose, and a rate-determining factor exists for xylose uptake. P. acerina SF23754 converted xylan almost completely to ethanol at $20-50 \mathrm{~g} / \mathrm{L}$ of xylan. At $100 \mathrm{~g} / \mathrm{L}$ of xylan, approximately $30 \mathrm{~g} / \mathrm{L}$ of xylobiose accumulated with almost no consumption, along with xylotriose. Ethanol fermentation of xylan by members of the genus Phlebia was recently reported by Kamei et al. [37]; the highest ethanol yield $(47 \%)$ was observed in a static culture of P. ludoviciana HHB9640 strain grown in $20 \mathrm{~mL}$ of a medium containing $20 \mathrm{~g} / \mathrm{L}$ of xylan. Therefore, based on the medium volume and ethanol yield, P. acerina SF23754 produced ethanol more efficiently than P. ludoviciana HHB9640, although there were some differences in the culture methods.

Changes in the endo- $1,4-\beta$-xylanase and $\beta$-xylosidase activities during fermentation are shown in Figure $5 \mathrm{~d}-\mathrm{f}$. Almost no difference was observed in the endo-1,4- $\beta$-xylanase activity with varying medium concentrations, and high activity was observed at the initial stage of culture. Contrastingly, the $\beta$-xylosidase activity increased over time at all medium concentrations, but decreased as the xylan concentration increased. P. acerina SF23754 consumed xylose in the medium completely up to $50 \mathrm{~g} / \mathrm{L}$ (data not shown), indicating its relative resistance to xylose. Accordingly, the decrease in ethanol production and yield by this fungus could be related to the decrease in $\beta$-xylosidase secretion associated with xylan concentration, which was affected by xylobiose generation when xylan decomposition increased in the medium at a specific concentration.

The above results indicated that a balanced production of these enzymes in P. acerina SF23754 resulted in good growth and relatively high ethanol yield at approximately $50 \mathrm{~g} / \mathrm{L}$ of xylan. Thus, the abovementioned fermentation profiles indicated that P. acerina SF23754 could directly produce ethanol from xylan by simultaneous saccharification and fermentation without any pretreatment or additional enzymes. 

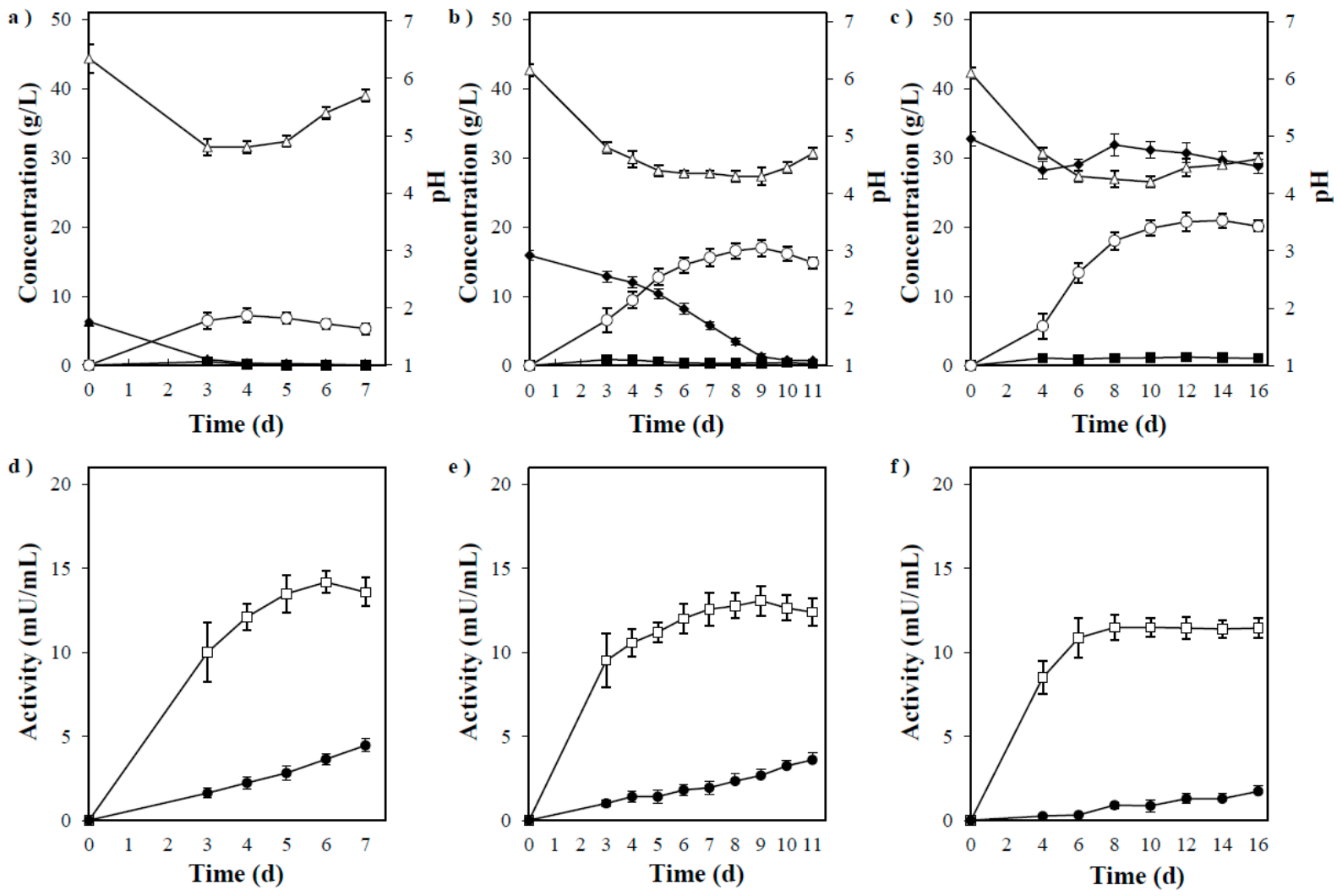

Figure 5. (a) Timeline of ethanol production by P. acerina SF23754 using $20 \mathrm{~g} / \mathrm{L}$ of xylan as the only carbon source and $10 \mathrm{~g} / \mathrm{L}$ of yeast extract. (b) Timeline of ethanol production by P. acerina SF23754 using $50 \mathrm{~g} / \mathrm{L}$ of xylan as the only carbon source and $10 \mathrm{~g} / \mathrm{L}$ of yeast extract. (c) Timeline of ethanol production by P. acerina SF23754 using $100 \mathrm{~g} / \mathrm{L}$ of xylan as the only carbon source and $10 \mathrm{~g} / \mathrm{L}$ of yeast extract. (d) Xylan-degrading enzyme activities in the medium containing 20/L and $10 \mathrm{~g} / \mathrm{L}$ of yeast extract during fermentation by P. acerina SF23754. (e) Xylan-degrading enzyme activities in the medium containing $50 \mathrm{~g} / \mathrm{L}$ of xylan and $10 \mathrm{~g} / \mathrm{L}$ of yeast extract during fermentation by P. acerina SF23754. (f) Xylan-degrading enzyme activities in the medium containing $100 \mathrm{~g} / \mathrm{L}$ of xylan and $10 \mathrm{~g} / \mathrm{L}$ of yeast extract during fermentation by P. acerina SF23754. Closed diamonds and squares represent xylobiose and xylose, respectively, while open circles and triangles represent ethanol and $\mathrm{pH}$, respectively. Open squares and closed circles represent endo- $1,4-\beta$-xylanase and $\beta$-xylosidase, respectively. Standard deviations were derived from three independent experiments and are indicated by error bars.

\subsection{Direct Ethanol Production from Acorn}

In the above tests, P. acerina SF23754 exhibited high fermentability for starch. Therefore, we studied acorns as a representative of plant biomass. Acorn powder added to water at a concentration of $10 \%(w / w)$ served as a medium without a nitrogen source. The powder dissolved poorly in the medium after autoclaving. This medium was compared with a medium containing the same concentration of starch $(60 \mathrm{~g} / \mathrm{L})$, and a double medium containing the same concentration of starch $(60 \mathrm{~g} / \mathrm{L})$ and the same concentration of tannic acid $(1 \mathrm{~g} / \mathrm{L})$, in which $10 \mathrm{~g} / \mathrm{L}$ yeast extract was added as a nitrogen source.

In the medium containing $1 \mathrm{~g} / \mathrm{L}$ of tannic acid, ethanol production was initiated late by approximately $6 \mathrm{~d}$ as compared with the control medium without tannic acid, but the concentrations of the ethanol produced in both the mediums were $24 \mathrm{~g} / \mathrm{L}$, and the yields per added starch were 70\%, thus indicating no differences (Figure 6a,b). This implied that the increase of mycelia in the early stage of growth was suppressed by tannic acid and caused a lag, but no significant effect was observed after the mycelia had grown to some extent, that is, $1 \mathrm{~g} / \mathrm{L}$ of tannic acid had no significant effects on the conversion of starch to ethanol in P. acerina SF23754, except for growth retardation. The residual tannic acid in the medium was lower than in the initial stage, suggesting partial decomposition of tannin by P. acerina SF23754. A delay in growth and fermentation was reported following 
the addition of $1 \mathrm{~g} / \mathrm{L}$ of tannin to the glucose medium in S. cerevisiae; however, the ethanol yield remained unaffected [20].
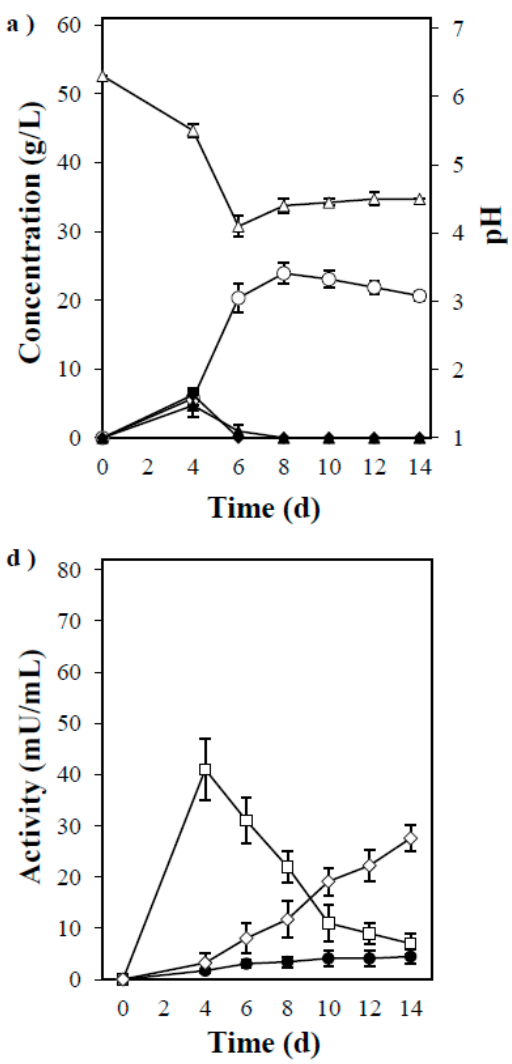
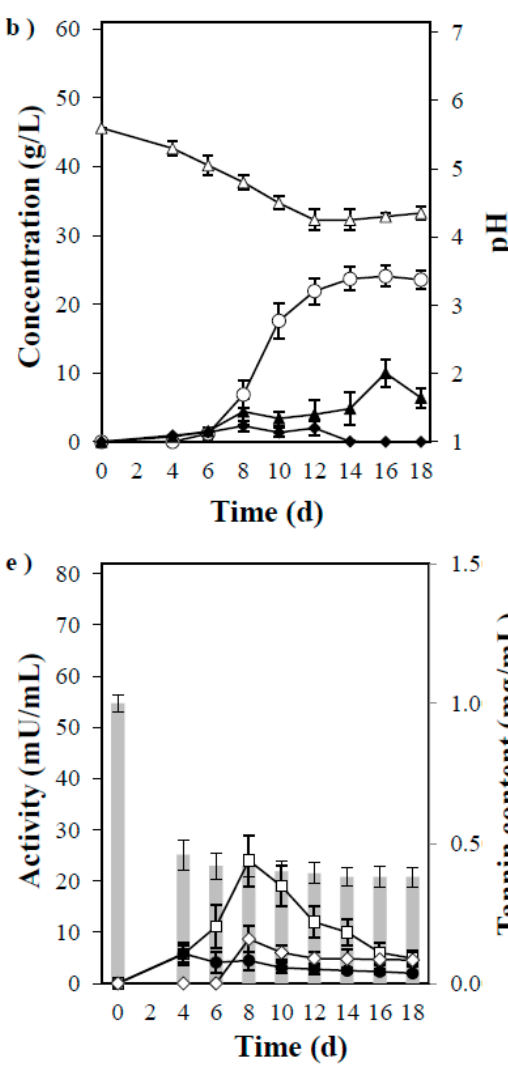

Figure 6. (a) Timeline of ethanol production by P. acerina SF23754 using $60 \mathrm{~g} / \mathrm{L}$ of starch. (b) Timeline of ethanol production by P. acerina SF23754 using $60 \mathrm{~g} / \mathrm{L}$ of starch and $1 \mathrm{~g} / \mathrm{L}$ of tannic acid. (c) Timeline of ethanol production by $P$. acerina SF23754 using $10 \mathrm{~g} / \mathrm{L}$ of acorn powder. (d) Amylolytic enzyme activities in the medium containing $60 \mathrm{~g} / \mathrm{L}$ of starch during fermentation by P. acerina SF23754. (e) Amylolytic enzyme activities in the medium containing $60 \mathrm{~g} / \mathrm{L}$ of starch and $1 \mathrm{~g} / \mathrm{L}$ of tannic acid during fermentation by P. acerina SF23754. (f) Amylolytic enzyme activities in the medium containing $10 \mathrm{~g} / \mathrm{L}$ of acorn powder during fermentation by P. acerina SF23754. Closed diamonds and triangles represent maltose and glucose, respectively, while open circles and triangles represent ethanol and $\mathrm{pH}$. Open squares, closed circles, and open diamonds represent $\alpha$-amylase, $\alpha$-glucosidase, and glucoamylase. Gray bars represent tannic acid. Standard deviations were derived from ten independent experiments and are indicated by error bars.

In contrast, the early stage of mycelial growth in P. acerina SF23754 was affected and showed prolonged ethanol production in a medium containing $10 \mathrm{~g} / \mathrm{L}$ acorn powder. The medium, which was initially gelatinous, gradually turned into a liquid, and its turbidity gradually cleared as fermentation progressed. Subsequently, the amount of tannin in the medium was lower than before fungal inoculation. Additionally, the antioxidant activity measured by the DPPH radical assay in the culture filtrate gradually decreased over time, and tannin was assumed to have decomposed during P. acerina SF23754 fermentation (data not shown). The fungus produced a maximum of $24 \mathrm{~g} / \mathrm{L}$ of ethanol from acorn powder and directly converted approximately $70 \%$ of the theoretical yield per added acorn powder (Figure 6c). Ethanol production in the medium containing $10 \mathrm{~g} / \mathrm{L}$ of acorn powder was almost the same as that in the medium containing $60 \mathrm{~g} / \mathrm{L}$ of starch and $1 \mathrm{~g} / \mathrm{L}$ of tannic acid. Ethanol production by $S$. cerevisiae was reported, in which fermentation was conducted using acorn flour saccharified with $\alpha$-amylase and glucose amylase with supplements added; subsequently, an ethanol yield of $69 \%$ was acquired. Furthermore, when tannin was removed, the maximum ethanol yield was $88 \%$ [18]. In P. acerina SF23754, the ethanol yield was $70 \%$ only from raw acorn powder without saccharification treatment, supplementation 
with yeast extract, and tannin removal treatment. However, when corn steep liquor was added to the acorn powder as a nitrogen source, the ethanol yield increased by more than $10 \%$ (data not shown). Thus, P. acerina SF23754 exhibited a relatively high conversion ability from raw materials, such as acorn, which contained starch and polyphenols.

The amylolytic enzyme activities are shown in Figure $6 \mathrm{~d}-\mathrm{f}$. The presence of tannin inhibited $\alpha$-amylase and glucoamylase activities by more than $50 \%$, thereby affecting saccharification from starch, which in turn delayed the mycelia growth and ethanol production. The activity differed marginally in the medium containing $10 \mathrm{~g} / \mathrm{L}$ of acorn powder from that of the medium containing $60 \mathrm{~g} / \mathrm{L}$ starch and $1 \mathrm{~g} / \mathrm{L}$ tannic acid, which had relatively high $\alpha$-glucosidase levels. This difference could be majorly due to the difference in the morphology of starch and tannin despite similar composition of the mediums containing acorn or the influence of other components.

Based on the above results, P. acerina SF23754 could directly convert ethanol with a relatively good yield even in the presence of tannin in the acorn.

\section{Conclusions}

The white rot basidiomycete fungus, Phlebia acerina SF23754, used in this study can assimilate a broad spectrum of carbon sources and ferment ethanol from xylan and starch. Our findings demonstrate the possibility of using acorn as a raw material for ethanol fermentation using this starch-degrading fungus for low-cost ethanol production, which may contribute to effective recycling and reduction of unused biomass. To the best of our knowledge, the isolated basidiomycete fungus strain, P. acerina SF23754, has not yet been reported for direct ethanol production from acorn. This strain proved to be a promising alternative for bioethanol production from renewable resources from the viewpoint of the abovementioned applications of raw materials; however, further studies should be conducted with a focus to improve the ethanol yield and productivity of this fungus. The study presents the proposal that direct ethanol production from renewable resources by a naturally occurring basidiomycete fungus can promote sustainable bioethanol production by consolidated bioprocessing since it can reduce the overall costs and the environmental footprint associated with conventional ethanol production methods.

Author Contributions: Conceptualization, K.O.; methodology, K.O.; investigation, K.O., T.G., T.Y., and M.N.; data analysis, K.O., T.G., T.Y., and M.N.; writing-original draft, K.O.; writing-review and editing, K.O.; supervision, K.O. All authors have read and agreed to the published version of the manuscript.

Funding: This research received no external funding.

Institutional Review Board Statement: Not applicable.

Informed Consent Statement: Not applicable.

Data Availability Statement: Not applicable.

Acknowledgments: The authors are thankful to Kunio Hiraga and Takayuki Niinuma for providing acorn.

Conflicts of Interest: The authors declare no conflict of interest.

\section{References}

1. IPCC. Climate Change 2013: The Physical Science Basis. Contribution of Working Group I to the Fifth Assessment Report of the Intergovernmental Panel on Climate Change; Stocker, T.F., Qin, D., Plattner, G.-K., Tignor, M., Allen, S.K., Boschung, J., Nauels, A., Xia, Y., Bex, V., Midgley, P.M., Eds.; Cambridge University Press: Cambridge, UK; New York, NY, USA, 2013 ; p. 1535.

2. Robak, K.; Balcerek, M. Review of second generation bioethanol production from residual biomass. Food Technol. Biotechnol. 2018, 56, 174-187. [CrossRef]

3. Saini, J.K.; Saini, R.; Tewari, L. Lignocellulosic agriculture wastes as biomass feedstocks for second-generation bioethanol production: Concepts and recent developments. 3 Biotech 2015, 5, 337-353. [CrossRef]

4. Machineni, L. Lignocellulosic biofuel production: Review of alternatives. Biomass Convers. Biorefin. 2020, 10, 779-791. [CrossRef] 
5. Zabed, H.; Sahu, J.N.; Boyce, A.N.; Faruq, G. Fuel ethanol production from lignocellulosic biomass: An overview on feedstocks and technological approaches. Renew. Sustain. Energy Rev. 2016, 66, 751-774. [CrossRef]

6. Saha, B.C. Hemicellulose bioconversion. J. Ind. Microbiol. Biotechnol. 2003, 30, 279-291. [CrossRef]

7. Girio, F.M.; Fonseca, C.; Carvalheiro, F.; Duarte, L.C.; Marques, S.; Bogel-Lukasik, R. Hemicelluloses for fuel ethanol: A review. Bioresour. Technol. 2010, 101, 4775-4800. [CrossRef]

8. Mood, S.H.; Golfeshan, A.H.; Tabatabaei, M.; Jouzani, G.S.; Najafi, G.H.; Gholami, M.; Ardjmand, M. Lignocellulosic biomass to bioethanol, a comprehensive review with a focus on pretreatment. Renew. Sustain. Energy Rev. 2013, 27, 77-93. [CrossRef]

9. Linko, M.; Viikari, L.; Suihko, M.L. Hydrolysis of xylan and fermentation of xylose to ethanol. Biotechnol. Advs. 1984, 2, $233-252$. [CrossRef]

10. Burchhardt, G.; Ingram, L.O. Conversion of xylan to ethanol by ethanologenic strains of Escherichia coli and Klebsiella oxytoca. Appl. Environ. Microbiol. 1992, 58, 1128-1133. [CrossRef] [PubMed]

11. Katahira, S.; Fujita, Y.; Mizuike, A.; Fukuda, H.; Kondo, A. Construction of a xylan-fermenting yeast strain through codisplay of xylanolytic enzymes on the surface of xylose-utilizing Saccharomyces cerevisiae cells. Appl. Environ. Microbiol. 2004, 70, 5407-5414. [CrossRef] [PubMed]

12. Sun, J.; Wen, F.; Si, T.; Xu, J.-H.; Zhao, H. Direct conversion of xylan to ethanol by recombinant Saccharomyces cerevisiae strains displaying an engineered minihemicellulosome. Appl. Environ. Microbiol. 2012, 78, 3837-3845. [CrossRef] [PubMed]

13. Vinha, A.F.; Barreira, J.C.M.; Costa, A.S.G.; Oliveira, M.B.P.P. A new age for Quercus spp. fruits: Review on nutritional and phytochemical composition and related biological activities of acorns. Compr. Rev. Food Sci. Food Saf. 2016, 15, 947-981. [CrossRef] [PubMed]

14. Alegria, C.; Antunes, C.; Giovanetti, M.; Abreu, M.; Máguas, C. Acorn isotopic composition: A new promising tool for authenticity maps of Montado's high-value food products. Molecules 2020, 25, 1535. [CrossRef]

15. Cantos, E.; Espín, J.C.; López-Bote, C.; de la Hoz, L.; Ordóñez, J.A.; Tomás-Barberán, F.A. Phenolic compounds and fatty acids from acorns (Quercus spp.), the main dietary constituent of free-ranged Iberian pigs. J. Agric. Food Chem. 2003, 51, 6248-6255. [CrossRef] [PubMed]

16. Cao, P.; Cai, J.; Gupta, R.C. Effect of green tea catechins and hydrolyzable tannins on benzo[a]pyrene-induced DNA adducts and structure-activity relationship. Chem. Res. Toxicol. 2010, 23, 771-777. [CrossRef] [PubMed]

17. Heidari, F.; Asadollahi, M.A.; Jeihanipour, A.; Kheyrandish, M.; Rismani-Yazdi, H.; Karimi, K. Biobutanol production using unhydrolyzed waste acorn as a novel substrate. RSC Adv. 2016, 6, 9254-9260. [CrossRef]

18. Pan, P.; Tang, Y.; Sun, D.; Jiang, J.; Song, X. Effect of ultrasonic-assisted pretreatment on hydrolysis and fermentation of acorn starch. BioResources 2014, 9, 2705-2716. [CrossRef]

19. Zarroug, Y.; Boulares, M.; Mejri, J.; Slimi, B.; Hamdaoui, G.; Djebi, S.; Saidi, F.; Nasri, H.; Sfayhi, D.T.; Kharrat, M. Extraction and characterization of Tunisian Quercus ilex starch and its effect on fermented dairy product quality. Int. J. Anal. Chem. 2020, 2020, 8868673. [CrossRef]

20. Chao, B.; Liu, R.; Zhang, X.; Zhang, X.; Tan, T. Tannin extraction pretreatment and very high gravity fermentation of acorn starch for bioethanol production. Bioresour. Technol. 2017, 241, 900-907. [CrossRef]

21. Zhang, N.; Jiang, J.C.; Yang, J.; Wei, M.; Zhao, J.; Xu, H.; Xie, J.C.; Tong, Y.J.; Yu, L. Citric acid production from acorn starch by tannin tolerance mutant Aspergillus niger AA120. Appl. Biochem. Biotechnol. 2019, 188, 1-11. [CrossRef]

22. Isroi, M.; Millati, R.; Syamsiah, S.; Niklasson, C.; Cahyanto, M.N.; Lundquist, K.; Taherzadeh, M.J. Biological pretreatment of lignocelluloses with white-rot fungi and its applications: A review. BioResources 2011, 6, 5224-5259. [CrossRef]

23. Mizuno, R.; Ichinose, H.; Honda, M.; Takabatake, K.; Sotome, I.; Takai, T.; Maehara, T.; Okadome, H.; Isobe, H.; Gau, M.; et al. Use of whole crop sorghums as a raw material in consolidated bioprocessing bioethanol production using Flammulina velutipes. Biosci. Biotechnol. Biochem. 2009, 73, 1671-1673. [CrossRef]

24. Horisawa, S.; Ando, H.; Ariga, O.; Sakuma, Y. Direct ethanol production from cellulosic materials by consolidated biological processing using the wood rot fungus Schizophyllum commune. Bioresour. Technol. 2015, 197, 37-41. [CrossRef] [PubMed]

25. Mattila, H.; Kuuskeri, J.; Lundell, T. Single-step, single-organism bioethanol production and bioconversion of lignocellulose waste materials by phlebioid fungal species. Bioresour. Technol. 2017, 225, 254-261. [CrossRef] [PubMed]

26. Kamei, I.; Hirota, Y.; Mori, T.; Hirai, H.; Meguro, S.; Kondo, R. Direct ethanol production from cellulosic materials by the hypersaline-tolerant white-rot fungus Phlebia sp. MG-60. Bioresour. Technol. 2012, 112, 137-142. [CrossRef] [PubMed]

27. Okamoto, K.; Imashiro, K.; Akizawa, Y.; Onimura, A.; Yoneda, M.; Nitta, Y.; Maekawa, N.; Yanase, H. Production of ethanol by the white-rot basidiomycetes Peniophora cinerea and Trametes suaveolens. Biotechnol. Lett. 2010, 32, 909-913. [CrossRef] [PubMed]

28. Okamoto, K.; Nitta, Y.; Maekawa, N.; Yanase, H. Direct ethanol production from starch, wheat bran and rice straw by the white rot fungus Trametes hirsuta. Enzym. Microb. Technol. 2011, 48, 273-277. [CrossRef]

29. Okamoto, K.; Sugita, Y.; Nishikori, N.; Nitta, Y.; Yanase, H. Characterization of two acidic $\beta$-glucosidases and ethanol fermentation in the brown rot fungus Fomitopsis palustris. Enzym. Microb. Technol. 2011, 48, 359-364. [CrossRef]

30. Okamoto, K.; Kanawaku, R.; Masumoto, M.; Yanase, H. Efficient xylose fermentation by the brown rot fungus Neolentinus lepideus. Enzym. Microb. Technol. 2012, 50, 96-100. [CrossRef]

31. Okamoto, K.; Uchii, A.; Kanawaku, R.; Yanase, H. Bioconversion of xylose, hexoses and biomass to ethanol by a new isolate of the white rot basidiomycete Trametes versicolor. Springerplus 2014, 3, 121. [CrossRef] 
32. Okamoto, K.; Yoneda, M.; Fumioka, T. Isolation of a Peniophora strain capable of producing ethanol from starch and kitchen waste. Ferment. Technol. 2017, 6, 1. [CrossRef]

33. Okamoto, K.; Nakagawa, S.; Kanawaku, R.; Kawamura, S. Ethanol production from cheese whey and expired milk by the brown rot fungus Neolentinus lepideus. Fermentation 2019, 5, 49. [CrossRef]

34. Gómez, S.; Payne, A.M.; Savko, M.; Fox, G.C.; Shepard, W.E.; Fernandez, F.J.; Vega, M.C. Structural and functional characterization of a highly stable endo- $\beta-1,4$-xylanase from Fusarium oxysporum and its development as an efficient immobilized biocatalyst. Biotechnol. Biofuels 2016, 9, 191. [CrossRef] [PubMed]

35. Singleton, V.L.; Rossi, J.A. Colorimetry of total phenolics with phosphomolybdic-phosphotungstic acid reagents. Am. J. Enol. Vitic. 1965, 16, 144-158.

36. Yamada, R.; Bito, Y.; Adachi, T.; Tanaka, T.; Ogino, C.; Fukuda, H.; Kondo, A. Efficient production of ethanol from raw starch by a mated diploid Saccharomyces cerevisiae with integrated $\alpha$-amylase and glucoamylase genes. Enzym. Microb. Technol. 2009, 44, 344-349. [CrossRef]

37. Kamei, I.; Uchida, K.; Ardianti, V. Conservation of xylose fermentability in Phlebia species and direct fermentation of xylan by selected fungi. Appl. Biochem. Biotechnol. 2020, 192, 895-909. [CrossRef] [PubMed] 